\title{
Planning and managing disruptive business models for RFID-startups-The disruptor's arrow of time
}

\author{
Rod King
}

Correspondence: rodkuhnking@ sbcglobal.net

Ideal-Solutions Management, 1630 E. Shaw Ave., Suite 163, Fresno, CA USA

\begin{abstract}
This paper presents a one-page visual tool for adaptively planning and managing potentially disruptive business models such as in RFID-Startups. The visual tool is called "The Disruptor's Arrow of Time." The modular and iterative approach of the Disruptor's Arrow of Time overcomes a serious limitation of Waterfall Business Planning, which rigidly focuses on a single chain of activities from planning to execution. Unlike in Waterfall Business Planning, the Disruptor's Arrow of Time uses a business model as unit of analysis, planning, design, and innovation. The Disruptor's Arrow of Time uses a four-stage process for business model planning and management. To illustrate benefits of using the Disruptor's Arrow of Time, the tool is used to present a case study on the systematic development and validation of a disruptive business model such as for Zipcar, which is an RFID-startup. Zipcar's example highlights the flexibility and effectiveness of the Disruptor's Arrow of Time in adaptively planning and managing disruptive business models particularly in the emerging epoch of the Internet of Things.
\end{abstract}

\section{Springer}

\section{Traditional planning and management of startups}

In 1942, the Austrian Economist Joseph Schumpeter proposed a theory of innovation which indicates that structural economic development arises out of the creative destruction or disruption of prior economic systems. In contrast to previous economists, Schumpeter advanced the idea that innovative entrepreneurs and startups constitute the disruptive force that drives and sustains economic growth. Nowadays, disruptive startups are regarded as the critical engine of economic growth and job creation in advanced free market economies. However, startups experience a high rate of failure. According to the Small Business Association of America, 50\% of startups die within five years. Seventy percent of businesses die within ten years from birth.

The core cause of the high rate of failure of startups is attributed to Waterfall Business Planning which is traditionally used to plan and deliver the products of startups $[1,2]$. Waterfall Planning typically follows a linear process such as in a single chain of activities: idea/concept generation, product development, product testing, and launch. The author in [1] regards the Waterfall Model as suitable for established companies that already have a validated and predictable business model: the product is known and used in a financially viable market with established channels and customers. In the

(c) 2012 King; licensee Springer. This is an Open Access article distributed under the terms of the Creative Commons Attribution License (http://creativecommons.org/licenses/by/2.0), which permits unrestricted use, distribution, and reproduction in any medium, provided the original work is properly cited. 
case of a budding startup, the business model is uncalibrated since the final version of the product is largely unknown and the startup does not have an established channel and customer base. In the latter situation, the startup has to adopt an experimental and adaptive approach in order to discover, calibrate, and validate its customer segment as well as financial viability of its business model. To date, however, many startups with unvalidated products have focused on developing and executing business and financial plans in the manner of established businesses with validated and profitable business models. In short, many startups are using Waterfall Business Planning. Consequently, many startups run out of money, time, and other resources before discovering and validating a profitable business model especially in a volatile environment.

Traditional tools for Waterfall Business Planning such as a voluminous business plan and detailed financial analysis are increasingly considered unnecessary for a startup that has not yet discovered and validated its customer segment as well as profitability of its business model. In the world of startups, especially in the area of disruptive technology, there is a shift towards planning approaches that are agile and adaptive, have a strong focus on customer growth, and use a business model as the unit of analysis.

\section{Business model as representation of a living organization}

There are many definitions of the term "business model." The author in [3] provides a comprehensive review of the concept, approach, and definition of "business model." However, no definition recognizes a business as a living system that is described in [4]. Consequently, current definitions of a business model ignore fundamental properties and attributes that govern competition, survival, and prosperity of living systems. In the absence of a direct link to living systems, the large existing body of knowledge on living systems cannot easily be transferred to the domain of planning, designing, evaluating, and managing business models. This paper therefore takes a living systems approach to defining a business model.

Here, a business model is defined as a story plot, visual representation, or dynamic simulation of a living organization that viably pursues and achieves a hierarchy of goals. A business model essentially presents a cause-and-effect logic of how a living organization creates, captures, delivers, and shares value in an ecosystem. In humancentered living organizations, the goal hierarchy of a business model can be derived from or directly related to the mission, vision, and/or core values of the organization. Every business model consists of three building blocks, which are summarized using the acronym of "DNA:" Design; Needs; Aspirations. A business model can be visually documented, analyzed, designed, evaluated, and managed using a DNA Map as in [5]. Additional file 1: Figure S1 shows a business model as a DNA Map at the highest level of abstraction while Additional file 1: Figure S2 shows details of a business model at a strategic level. These diagrams indicate the multi-level and fractal nature of a business when represented as a living organization.

\section{Adaptively planning and managing the business model strategy of startups}

According to [6], a business typically gains competitive advantage by using one of three trade-off strategies: Overall Cost Leadership (Low Cost) Strategy, Differentiation Strategy, or Focus (Niche) Strategy. The author in [6] considers the zero trade-off strategy 
of Low Cost and High Differentiation as possible but highly improbable to realize. In [7], the authors identify Blue Ocean Strategy as a process that involves the simultaneous pursuit of Low Cost and Differentiation. The authors present case studies on a number of companies such as Cirque du Soleil, Southwest Airlines, Curves, and Yellow Tail that have pursued Blue Ocean Strategy and achieved extraordinary business success. These aforementioned companies have used "Value Innovation," which is the strategic logic behind Blue Ocean Strategy that is described in [7]. Value Innovation focuses on breaking the Value (Differentiation) vs. Cost trade-off while creating an uncontested market space. Additional file 1: Figure S3 shows types of business model strategies in an industry.

From the perspective of Strategy, this paper focuses on three archetypal business models for the success of startups: Low-cost Business Model; High Differentiation Business Model; Blue Ocean Business Model. Each business model is associated with a specific type of customer segment and strategy, namely, low-end customers (overserved/ unserved; good enough technology; low profit margin); high-end customers (underserved; high-end technology; high profit margin); Blue Ocean business model (overserved/unserved; good enough or advanced technology; highly profitable Return On Investment). In this paper, the author suggests that the process for using the Disruptor's Arrow of Time should be based on the Four-Stage Framework of Value Disruption Design [5]. Stage 1 involves attractiveness and risk ("SWOT") analysis of the situation in an existing industry and environment ("Red Ocean"). In the second stage, the startup decides whether to use a low cost, high differentiation, or Blue Ocean strategy/business model. In the third stage, the startup should explore, calibrate, and validate its initially selected strategy and business model for the disruption journey. After business model validation, the startup can focus on the fourth stage of profitability, scaling, and defensibility of its business model. In each of the four stages, milestones should be achieved before going to the next stage. This "milestone" approach reflects a core principle of Discovery-Driven Planning that is described in [8].

\section{The disruptor's arrow of time}

The planning and management of a potentially disruptive organization involves four Disruption Questions which are described in [5] as follows:

1. Why disrupt system?

2. What system to disrupt?

3. What system to disrupt to?

4. How best to disrupt system?

The four Disruption questions relate to the three question-tags of Why, What, and How that are used for organizing information and knowledge in projects as in [9]. For the planning and management of business model projects such as in a startup, the four Disruption Questions are organized in the following list:

1. Ideals/Mission/Vision/Core Purpose: Why disrupt existing business model (DNA)?

2. Present: What existing business model (DNA) to disrupt?

3. Future: What future business model (DNA) to disrupt to? 
4. Process (Strategy): How best to disrupt existing business model (DNA) in order to obtain future business model (DNA)?

Additional file 1: Figure S4 shows a one-page template for the Disruptor's Arrow of Time, which visually summarizes the above questions. The Disruptor's Arrow of Time, which is described in [5], is a one-page visual tool for Value Disruption Design [5] and in particular, universal storytelling, problem-modeling, problem-solving, planning, design, and innovation. As a worksheet, the Disruptor's Arrow of Time is used to plan, execute, and manage the disruption strategy and business model of startups as well as established businesses. Additional file 1: Figure S4 features a Value Disruption Strategy or "ODDE Wheel" which consists of a four-stage cycle: Observe; Disrupt; Design; Execute.

\section{The disruptive business model of Zipcar, an RFID-startup}

Founded in the year 2000, Zipcar is a membership-based carsharing company that has its headquarters in Cambridge, Massachusetts, USA. Zipcar provides vehicle reservations and usage to its members, whom it bills by the hour or day of usage. Zipcar's fleet of vehicles has RFID transponders that are located on the windshield. These RFID tags make it possible for customers to lock and unlock the doors of vehicles for their use. Zipcar is currently a Publicly Traded company and has branches in USA, Canada, and United Kingdom. It employs over 400 people.

Compared to traditional vehicle rental companies in the USA such as Enterprise Rent-A-Car, Hertz, and Avis, the business model of Zipcar is considered to be disruptive. Zipcar positions itself as being in the industry and business of "carsharing" and not in the business of car rentals. Zipcar's RFID technology allows it to offer a type of service (online membership and wireless carsharing) that is unique in the industry of renting and sharing vehicles. Additional file 1: Figure S5 illustrates diverse business model strategies in the industry of renting and sharing vehicles.

Additional file 1: Figure S6 provides an overview of Zipcar's disruptive business model innovation which is in contrast to the sustaining business model of Enterprise Rent-a-Car and Hertz. Zipcar's Arrow of Time can be used for branding, positioning, and articulating as well as adaptively planning and managing its disruptive business model. Details of Zipcar's validated business DNA model are shown in Additional file 1: Figure S7. Although the business model of Zipcar is now validated, there are constant changes and competitive threats in the environment. For instance, Hertz has started using RFID cards instead of keys in its car rental service. Consequently, Zipcar has to constantly review, adapt, and manage its business model. Additional file 1: Figure S8 shows the resources that Zipcar should use in order to achieve its value proposition and mission. Tools such as the Disruptor's Arrow of Time as well as business DNA model and map would help businesses especially scalable RFID-startups such as Zipcar to adaptively plan and manage business models in their lifecycles.

\section{Final remarks}

In today's highly volatile environment, traditional and linear tools such as Waterfall Business Planning are ill-suited for planning and managing risks of startups that are 
inherently disruptive and have unvalidated business models. To increase the odds of success for potentially disruptive startups, adaptive planning and management tools such as the Disruptor's Arrow of Time would have to be used. As a one-page visual tool, the Disruptor's Arrow of Time facilitates not only the presentation and articulation of a startup's mission, vision, and brand but also management of its strategy and evolving business model. Additional file 1: Figure S6 shows an example of how the Disruptor's Arrow of Time can be used to visually summarize the Value Disruption Strategy and evolution of the business model of a disruptive startup such as Zipcar. The Blue (Dream) Ocean Model of Zipcar strongly contrasts the Red (Nightmare) Ocean Model of Enterprise and Hertz. Zooming in on the Blue (Dream) Ocean of Zipcar's Arrow of Time reveals details of Zipcar's future or Blue Ocean business model, which is shown in Additional file 1: Figure S7. In order to realize the desired results of Zipcar's Blue Ocean business model, a suitable project team would have to implement and manage Zipstar's business model strategy and tactics as shown in Additional file 1: Figure S8. In the emerging era of the Internet of Things, the Disruptor's Arrow of Time will play a significant role in the successful evolution of potentially disruptive startups especially those using RFID technology.

\section{Additional file}

Additional file 1: Figure S1. Visionary business model: Overview of the logic of a DNA map. Figure S2. Strategic business model: Details of DNA map. Figure S3. Aspiration map for archetypal business model strategies. Figure S4. Disruptor's arrow of time: Template for value disruption. Figure S5. Aspiration map for business model strategies in rental vehicle industry. Figure S6. Zipcar's arrow of time for value disruption design of rental vehicle industry. Figure S7. Zipcar's blue ocean-business model in the USA. Figure S8. Zipcar's disruptive business model strategy \& tactics.

Received: 9 August 2012 Accepted: 13 August 2012

Published: 13 September 2012

\section{References}

1. Blank SG (2007) The four steps to the epiphany. USA, Quad/Graphics

2. Blank S, Dorf B (2012) The startup owner's manual: The step-by-step guide for building a great company. K \& S Ranch, Inc, California

3. Wirtz BW (2011) Business model management. Wiesbaden, Gabler Verlag

4. Miller JG (1978) Living systems. McGraw-Hill, Inc, New York

5. King R (2012) Underdog to top dog: How Leaders like Steve Jobs and Apple create disruptive business models. California, Ideal-solutions management

6. Porter ME (1980) Competitive strategy: Techniques for analyzing industries and competitors. The free press, New York

7. Kim WC, Mauborgne R (2005) Blue ocean strategy. Harvard business school press, Massachusetts

8. McGrath RG, MacMillan I (2009) Discovery-driven growth: A breakthrough process to reduce risk and seize opportunity. Harvard business press, Massachusetts

9. Rouse WB (1991) Design for success. John Wiley \& Sons, Inc, New York

doi:10.1186/2192-1121-1-5

Cite this article as: King: Planning and managing disruptive business models for RFID-startups-The disruptor's arrow of time. Communications in Mobile Computing 2012 1:5. 